\title{
Concepts behind the development of multiple drug therapy regimens in leprosy
}

\section{F R WATERS}

Hospital of Tropical Medicine, London NW1 OPE, United Kingdom

Dapsone monotherapy was, for about 30 years, the standard treatment for all types of leprosy. At first very successful, it failed because of three inter-related factors, namely poor compliance, the emergence of dapsone resistance, and the phenomenon of bacterial persistence, the most important being drug resistance.

The Problem

1. Poor compliance

Dapsone monotherapy was long-term therapy. Tuberculoid patients were treated from 18 months to 5 years (1), usually the latter in borderline-tuberculoid (BT) leprosy. Multibacillary patients were advised to stay on dapsone for a full 10 years after achieving skin smear negativity (2), although most lepromatous (LL) patients were, in fact, left on treatment for life. Yet patients seldom saw much improvement after the first 2 or 3 years of therapy, whereas further deterioration could occur from reactions or from secondary damage in anaesthetic limbs. Furthermore, relapses very seldom occurred within months of stopping therapy. Therefore, many patients absconded (more than 508 in one large study, within 4 years of starting treatment (3)), others only attended irregularly, and even among those who collected their dapsone each month, many failed to take their tablets regularly (4). Treatment was far too prolonged for good compliance.

2. Dapsone resistance (DR)

Although DR was sought during the first decade of dapsone monotherapy, it was said not to occur. The late emergence of dapsone-resistant Mycobacterium leprae is known to be due to the bacterium's prolonged generation time of 11 - 12 days and to the high peak blood level obtained with $100 \mathrm{mg}$. dapsone, some 500 times the minimum inhibitory concentration for fully sensitive strains. When proven DR was first reported by pettit 
and Rees in 1964 (5), it was thought to be a rare phenomenon, with an estimated prevalence in Malaysia of 0.28 and an annual incidence of 0.18 (6). By $1981,10.18$ of all registered LL and Borderline-lepromatous (BL) patients in West Malaysia were considered dapsone resistant, a full half being laboratory proven, although a few primary DR cases were included in this figure. In Ethiopia, the minimal proven prevalence was also around 10\%, although a realistic estimate was $19 \%$ (7); the prima facie incidence was about $3 \%$ per annum (8), and only fell slightly, to around 28 per annum, following the (re)introduction of full-dose dapsone (9). (The definition of proven dapsone resistance in the last report (9) differs from that used in the earlier reports). Most other areas where surveys of secondary dapsone resistance have been performed, gave prevalences in the region of $5-10 \%$.

Secondary dapsone resistance has normally only been detected in $L L$ and $B L$ patients. The incubation period between commencing sulphone (that is, dapsone in nearly all patients since 1950) therapy and the time of relapse has been found to be prolonged, but to vary greatly from patient to patient. In Malaysia, an analysis of the first 100 proven cases gave a range of 5 - 24 years, with an average of 15.8 years (10). Most had full dose DR, that is, resistance to 50-100 mg. dapsone given daily. In Ethiopia, the range for 174 patients reported in 1979 (7) was 2 - 21 years with an average of 9.7 years, reflecting the low dapsone dosage commonly used in the previous decade. Most had low or intermediate resistance, equivalent to a dosage of 1 or $10 \mathrm{mg}$. daily. But the threat of dapsone resistant relapse, although it may diminish with time beyond 20 years, still appears to persist indefinitely in LL and $\mathrm{BL}$ patients remaining on dapsone monotherapy. I have studied two patients, who both commenced therapy with solapsone in 1947 and were subsequently maintained on dapsone, who relapsed in 1980 and 1984 respectively, the latter patient receiving all his 37 years' treatment while living in leprosy-free areas. When $L L$ and $B L$ patients relapse with secondary DR, they eventually become infectious once again. Their contacts are infected with resistant bacilli, and those unable to overcome the infection subclinically develop primary dapsone resistant leprosy of any type, including BT, TT and Indeterminate. Primary $D R$ is easier to study in LL and BL 
patients as their strains of M.leprae can be subjected to dapsone-sensitivity testing in mice. It has been detected in many parts of the world. The highest prevalences were found in the WHO THELEP drug trials, $35 \%$ in Chingleput and $37.5 \%$ in Bamako (11), although most strains showed only low-level resistance. Resistance in tuberculoid leprosy has recently been reported (12); it is probable that it has been widely overlooked in the past.

The subject of DR has been well reviewed by Pearson in 1981 (13) and by Ji in 1985 (14).

\section{Microbial persistence}

Bacterial persistence - the survival of small numbers of drug-sensitive bacilli after the dramatic initial kill with appropriate and continuing chemotherapy - is as important in leprosy as it is in other bacterial diseases such as tuberculosis, typhoid and subacute bacterial endocarditis. Such persisters, in leprosy thought to be physiologically dormant bacilli, can cause relapse after stopping effective chemotherapy.

Waters et al (15) isolated dapsone sensitive strains of $\mathrm{M}$. leprae from 3 of 12 LL patients treated 10 - 12 years with standard dapsone therapy under good conditions. The same group studied $362 \mathrm{LL}$ and BL in-patients treated in Malaysia for 18.5 - 22 years up to 1970 with supervised dapsone monotherapy, and who then stopped chemotherapy (16). Over the next 8 - 9 years, 25 patients (8.88) relapsed; in a third of these, the dapsone sensitivity of their strains of M.leprae was determined, and half were fully dapsone sensitive and half showed various levels of DR. Therefore in a small proportion of patients treated exceptionally regularly and well with dapsone monotherapy, persistent bacilli might survive for at least as long as 20 years.

\section{Concepts behind the solution}

1. Drug resistant mutants and the size of the bacterial population

By analogy with tuberculosis, it is known that in a bacterial population, prior to any treatment, there exists a small, genetically-determined sub-population resistant to a drug. The size of the sub-population varies with the drug used, but is usually of the order of one in $10^{6}$ M.tuberculosis. The chance 
that any bacillus is resistant to two drugs is one in $10^{12}$. It is thought that the frequency of resistant mutants is similar in M.leprae populations. Resistance to rifampicin and to ethionamide/prothionamide after monotherapy with these drugs has already been described, although only one strain of clofazimine-resistant M.leprae has been reported to date (17), even though this last drug has been used since 1962 .

It is estimated that an advanced, untreated case of LL may have a bacterial population of $10^{12}$ M.leprae, of which $10^{11}$ are viable. It is therefore essential to treat all multibacillary leprosy (MBL) with three bactericidal drugs, especially as DR might already be present, whether primary or secondary. On the other hand, untreated BT, TT and Indeterminate patients having no smear site as high as $2+$ on the Ridley scale (paucibacillary leprosy, PBL), are thought to have a viable bacterial population of less than $10^{6}$ as well as most possessing (or developing) significant cell-mediated immunity. Monotherapy with one bactericidal drug other than dapsone is therefore sufficient. But because of the risk of misclassification under field conditions, or the possibility of having a higher than expected bacterial population in nerves, though not in the skin, it is safer to give therapy with two drugs, although the second could be dapsone as most primary DR is still low level.

2. Persistence and compliance

It has been found in tuberculosis, that the shorter the duration of therapy, the better is the compliance. Furthermore, it has been shown in Ethiopia and Ruanda (18) that eight weekly $900 \mathrm{mg}$. doses of rifampicin cured PBL, as did a somewhat different short-course regimen of rifampicin and acedapsone in the Philippines (19). Most of the small number of "relapses" now being reported following wHO short-course rifampicin plus dapsone chemotherapy in PBL are probably due to late reversal reactions and not to renewed bacillary multiplication and spread. The PBL multidrug therapy appears to be very well founded.

There is perhaps more uncertainty over the treatment of MBL. Persisters have been detected after 5 years of rifampicin (20) and 15 years of clofazimine (21) monotherapy (prothionamide has not been studied). Nevertheless, combined daily dapsone and rifampicin therapy has been shown to produce fewer persisters at 6 months than dapsone monotherapy (22). In the Malta trial, 
where combined chemotherapy with daily rifampicin and Isoprodian (dapsone, prothionamide and isoniazid) was administered to a very mixed group of patients, for about 24 months, Jopling (23) reviewed $116 \mathrm{MBL}$ patients most of whom had been followed 6 - 9 years since stopping all anti-leprosy chemotherapy. None had relapsed clinically or bacteriologically, although 34 were still weakly smear-positive. Moreover, rifampicin given on two consecutive days each month has proved as effective as daily rifampicin, as judged by persister detection at 5 years (24). Similarly, in the THELEP controlled drug trial in MBL, a single dose of $1500 \mathrm{mg}$. rifampicin was as effective as $600 \mathrm{mg}$. daily over 2 years (25).

We may conclude that the WHO MBL regimen, selected on grounds of cost, effectiveness (including the prevention of the emergence of rifampicin resistance), acceptability, supervisability and low toxicity, is amply fulfilling its hopes for controlling drug resistance where it is conscientiously and efficiently being applied. The recent THELEP work (25) suggests that the regimen may well be found to be as fully effective in controlling persistence as any other so far investigated, and that it is not a second-best. We may use it with full confidence.

\section{References}

1 World Health Organization Expert Committee on Leprosy 3rd Report 1966. Wld Hlth Org techn Rep Ser No.319.

2 World Health Organization Expert Committee on Leprosy 4 th Report 1970. Wld Hlth Org techn Rep Ser No. 459.

3 Collier PJ. A study of case-holding in leprosy patients in Asia, based on duration of treatment, 1976-80. Lepr Rev, 1983, 54, 89-94.

4 Ellard GA. Editorial: Drug compliance in the treatment of leprosy. Lepr Rev, 1981, 52, 201-213.

5 Pettit JHS, Rees RJW. Sulphone resistance in leprosy. An experimental and clincial study. Lancet, 1964, $\underline{2}$, 673-674.

6 Pettit JHS, Rees RJW, Ridley DS. Studies on sulfone resistance in leprosy. 1. Detection of cases. Int J Leprosy, $1966, \underline{34}, 375-390$. 
7 Pearson JMH, Haile GS, Barnetson RStC, Rees RJW. Dapsone-resistant leprosy in Ethiopia. Lepr Rev, 1979, 50,183-199.

8 Pearson, JMH, Cap JA, Haile GS, Rees RJW. Dapsoneresistant leprosy and its implications for leprosy control programmes. Lepr Rev, 1977, 48, 83-94.

9 Warndorff van Diepen $T$, Mengistu G. Relapse rate and incidence of dapsone resistance in lepromatous leprosy patients in Addis Ababa: risk factors and effect of short-term supplementary treatment. Int J Leprosy, 1985, 53, 189-197.

10 Pearson, JMH, Rees RJW, Waters MFR. Sulphone resistance in leprosy. A review of one hundred proven clincal cases. Lancet, $1975, \underline{2}, 69-72$.

11 Sub-Committee on Clinical Trials of World Health Organization THELEP. Primary resistance to dapsone among untreated lepromatous patients in Bamako and Chingleput. Lepr Rev, 1983, 54, 177-183.

12 Pearson JMH, Kiran KU, Stanley JNA. Primary dapsone resistant tuberculoid leprosy. Indian J Lep, 1984, $\underline{56}$, (Supplement) XII International Leprosy Congress, Abstract No. III/165.

13 Pearson JMH. The problem of dapsone-resistant leprosy. Int J Leprosy, 1981, $\underline{49}, 417-420$.

$14 \mathrm{Ji}$ B. Drug resistance in leprosy - a review. Lepr Rev, $1985, \underline{56}, 265-278$.

15 Waters MFR, Rees RJW, McDougall AC, Weddell AGM. Ten years of dapsone in lepromatous leprosy: clinical, bacteriological and histological assessment and the finding of viable leprosy bacilli. Lepr Rev, 1974, 45, 288-298.

16 Waters MFR, Rees RJW, Laing ABG, Khoo KF, Meade TW, Parikshak N, North WRS. The rate of relapse in lepromatous leprosy following completion of twenty years of supervised sulphone therapy. Lepr Rev, 1986, 57, in press.

17 Warndorff van Diepen T. Clofazimine-resistant leprosy, a case report. Int J Leprosy, 1982, 50, 139-142.

18 Warndorff $J$, Bourland J, Pattyn SR. Follow-up on short course two months rifampicin treatment of paucibacillary leprosy. Lepr Rev, 1982, 53, 9-17. 
19 World Health Organization Report of the third meeting of the Scientific Working Group on the chemotherapy of leprosy, Geneva, 20-22 October 1980. Unpublished World Health Organization document - TDR/THELEP - SWE(3)/80.3.20 Waters MFR, Rees RJW, Pearson JMH, Laing ABG, Helmy HS, Gelber RH. Rifampicin for lepromatous leprosy: nine years' experience. Br Med J, 1978, 1, 133-136.

21 Waters MFR, Rees RJW, Pearson JMH, Laing ABG. Detection of persisting Mycobacterium leprae during long term treatment of dapsone-resistant lepromatous leprosy with clofazimine. In preparation.

22 Gelber RH, Waters MFR, Pearson JMH, Rees RJW, McDoughall AC. Dapsone alone compared with dapsone plus rifampicin in short-term therapy of lepromatous leprosy. Lepr Rev, 1977, $\underline{48}, 223-229$.

23 Jopling WH, Ridley MJ, Bonnici E, Depasquale G. A follow-up investigation of the Malta Project. Lepr Rev, 1984, $\underline{55}$, 247-253.

24 Laing ABG, Waters MFR, Rees RJW. Four-weekly "pulse" therapy with rifampicin in sulphone-resistant lepromatous leprosy - interim report. Int J Leprosy, 1979, 47, 437.

25 Sub-Committee on Clinical Trials of World Health Organization THELEP. Persisting Mycobacterium leprae among THELEP Trial patients in Bamako and Chingleput. In preparation. 